\title{
Elucidating the trophic ecology of foraging leatherback turtles: editorial comment on the feature article by Wallace et al.
}

\author{
Rebecca Lewison
}

Received: 19 May 2014 / Accepted: 21 May 2014 / Published online: 6 June 2014

(C) Springer-Verlag Berlin Heidelberg 2014

Leatherback sea turtles are ocean travelers, moving hundreds and often thousands of kilometers each year. In the Atlantic Ocean, leatherbacks' range (Dermochelys coriacea) extends from breeding grounds in the Caribbean to foraging areas in boreal waters off Nova Scotia, Canada. Despite decades of research, there are still major gaps in our knowledge of the basic biology and ecology of this marine giant. These gaps in knowledge have serious implications: Leatherbacks are a species of conservation concern worldwide, identified as an endangered species in the USA and Canada and internationally as Vulnerable by the IUCN Red List (IUCN 2013). In-water management and protection of leatherbacks is an ongoing and global challenge.

Long-term monitoring (genetic and telemetry) has been used to describe migratory and other movement patterns, diving behavior, and population structure, i.e., nesting origins (James et al. 2005a, b, c, 2006, 2007; Stewart et al. 2013). While it's known that leatherbacks feed almost exclusively on large scyphozoan jellyfish (Cyanea capillata, Chrysaora quinquecirrha), relatively little is known regarding the degree of trophic variation within and among cohorts. This variation could result from differences in ontogenetic or reproductive development or differences in horizontal or vertical distribution in the ocean. With a robust sample from over 100 foraging individuals, Wallace et al. (2014) address this knowledge gap using stable isotopes, which are naturally occurring forms of an element, commonly carbon and nitrogen, that differ in atomic mass.

Communicated by U. Sommer.

R. Lewison $(\bowtie)$

Biology Department, San Diego State University, 5500 Campanile Drive, San Diego, CA 92182, USA

e-mail: rlewison@mail.sdsu.edu
To date, the research on characterizing the diet and trophic status of leatherbacks has been conducted in nesting grounds, in large part because of the ease of sampling nesting females. In contrast, Wallace et al. focus their attention on the trophic status of foraging, instead of nesting, leatherbacks in Canadian waters. Their study find significant differences in nitrogen isotopic values as a function of body size, a proxy for age, but detected no differences between male and female adults. The authors conclude that the observed isotopic differences may be driven by different isotopic incorporation rates as leatherbacks grow or by differences in behavior and physiology based on reproductive status, two hypotheses that are supported by existing research. The findings from Wallace et al. help direct future research and the authors outline new analytical and empirical approaches that can resolve these unanswered questions.

What do we learn by elucidating the trophic ecology of foraging leatherbacks? Understanding the drivers of trophic status variation is fundamental to identifying important foraging areas, ocean habitat that is critical for management and protection of this imperiled species. The status and fate of foraging individuals, ultimately, determines long-term population dynamics. The results from Wallace et al. demonstrate the importance of contextualizing findings within an ocean basin context to adequately assess trophic ecology, population status, and dynamics of widely distributed, highly migratory species like leatherbacks.

\section{References}

IUCN (2013) IUCN red list of threatened species. Version 2013.2. www.iucnredlist.org. Downloaded 14 May 2014

James MC, Myers RA, Ottensmeyer CA (2005a) Behaviour of leatherback sea turtles, Dermochelys coriacea, during the migratory cycle. Proc R Soc B 272:1547-1555 
James MC, Ottensmeyer CA, Myers RA (2005b) Identification of high-use habitat and threats to leatherback sea turtles in northern waters: new directions for conservation. Ecol Lett 8:195-201

James MC, Eckert SA, Myers RA (2005c) Migratory and reproductive movements of male leatherback turtles (Dermochelys coriacea). Mar Biol 147:845-853

James MC, Sherrill-Mix SA, Martin K, Myers RA (2006) Canadian waters provide critical foraging habitat for leatherback sea turtles. Biol Conserv 133:347-357

James MC, Sherrill-Mix SA, Myers RA (2007) Population characteristics and seasonal migrations of leatherback sea turtles at high latitudes. Mar Ecol Prog Ser 337:245-254
Stewart KR, James MC, Roden S, Dutton PH (2013) Assignment tests, telemetry and tag-recapture data converge to identify natal origins of leatherback turtles foraging in Atlantic Canadian waters. J Anim Ecol. doi:10.1111/1365-2656.12056

Wallace B, Schumacher J, Seminoff JA, James MC (2014) Biological and environmental influences on the trophic ecology of leatherback turtles in the Northwest Atlantic Ocean. Mar Biol (This issue) 